\title{
Association of platelet count and platelet indices with stages of women breast cancer in Yola, Nigeria
}

\begin{abstract}
Background/objective: Platelets are involved in mechanisms that promote tumor growth. Platelet indices are marker of platelet activities in cancer. Platelet indices includes: mean platelet volume (MPV), platelet distribution width (PDW), Plateletocrit (PCT), Platelet large cell ratio (P-LCR). This study aims to evaluate platelet count and platelet indices at different stages of women breast cancer in Yola.
\end{abstract}

Materials and methods: I43 women participated in this study. Platelet count and platelet indices were determined using Sysmex XP 300 hematology analyzer.

Results: Mean platelet count in women with stage $0 / 1$, 2, and 3/4, was $207 \pm 23.09 \times 10^{9} / 1$, $1 \mid 3 \pm 14.58 \times 10^{9} / 1$ and $412 \pm 12.50 \times 10^{9} / \mid$ respectively. While mean PDW in women with stage $0 / I, 2$, and $3 / 4$, breast cancer was $I I .9 \pm 0.2 \mathrm{Ifl}, \mid 3 . I \pm I$. If $\mathrm{f}$ and $I 2 . I \pm 0.30 \mathrm{fl}$ respectively. MPV of women with stage $0 / I, 2$, and $3 / 4$, breast cancer was $12.0 \pm I .20 \mathrm{fl}, \mid 3.9 \pm 0.26 \mathrm{fl}$ and $14.4 \pm 0.08 \mathrm{fl}$ respectively. The mean P-LCR of women with stage $0 / 1$ breast cancer was $32.4 \pm 0.88 \%$ while P-LCR of those with stage 2 and $3 / 4$ breast cancers was $21.8 \pm 1.64 \%$ and $19.3 \pm 1.13 \%$ respectively. Mean PCT of women on stage $0 / 1,2,3 / 4$ was $0.23 \pm 0.13 \%$, $0.12 \pm 1.02 \%$ and $0.29 \pm 0.20 \%$ respectively.

Conclusion: Platelet counts and platelet indices vary with stages of breast cancer. Pattern of MPV variations indicates that MPV can be used as indices to measure platelet activation, tumor metastasis/invasion and inflammatory processes in women with breast cancer in Yola Nigeria.

Keywords: platelet count, platelet indices, breast cancer
Volume 6 Issue I - 2018

\author{
Emmanuel Asuquo Etim,' Mathias Abiodun \\ Emokpae, ${ }^{2}$ Adjekuko Collins Ohwonigho, ${ }^{3}$ \\ Abdulakeem Adebayo Yusuf' \\ 'Laboratory Department, Federal Medical Centre, Nigeria \\ ${ }^{2}$ Department of Medical Laboratory Science, University of \\ Benin, Nigeria \\ ${ }^{3}$ Department of Medical Laboratory Services, General Hospital \\ Okwe-Asaba, Nigeria
}

Correspondence: Emmanuel Asuquo Etim, Laboratory Department, Federal Medical Centre, Yola, Adamawa State, Northeast Nigeria, Tel +2348063924735,

E-mail emmasuti@yahoo.com

Received: October 28, 2017 | Published: February 07, 2018
Abbreviations: MPV, mean platelet volume; PDW, platelet distribution width; PCT, plateletocrit; P-LCR, platelet large cell ratio

\section{Introduction}

Platelets are anucleated cells derived from megakaryocytes. ${ }^{1}$ Platelets are multifunctional in nature and apart from playing a key role in hemostasis processes, ${ }^{2}$ platelets are also involved in mechanisms that promotes tumor growth and metastasis. ${ }^{3,4}$ Platelets secrete various growth factors and cytokines that promote angiogenesis, tumor growth, invasion and metastasis of cancer cells either directly or indirectly. ${ }^{5}$ There are reports that thrombocytosis contributes to cancer metastasis. ${ }^{6-8}$ In women with breast cancer, an increased circulating platelet is associated with poor cancer prognosis,, 910 and the ability of breast tumor cells to induce platelet aggregation correlates with their metastatic potential. ${ }^{11}$ Studies in breast cancer models have also shown that direct interaction between breast cancer cells and platelets results in the activation of TGF- $\beta$ (transforming growth factor-beta) signaling pathway, which promotes metastasis, and invasion of cancer cell by inducing epithelial-to-mesenchymal transition and immunosuppression ${ }^{12,13}$ and breast cancer cells have been shown to prepares platelets to release pro-angiogenic proteins which stimulate migration and proliferation of cancer cells. ${ }^{14}$ Platelets also stimulate the release of pro-inflammatory cytokines (interleukin 1,3, and 6) by cancer cells ${ }^{15}$ to enhance cancer progression.

Platelet indices are part of routine automated full blood counts. Platelet indices includes:

i. Mean Platelet Volume (MPV), which is a measurement of average platelets size ${ }^{16}$ ii. Platelet Distribution Width (PDW), which is a measure of variability in platelet sizes

iii. Plateletocrit (PCT), which indicates the volume of circulating platelets in a unit volume of blood ${ }^{17}$ and

iv. Platelet Large Cell Ratio (P-LCR) which is a good aid in differential diagnosis of conditions associated with abnormal platelet counts..$^{18,19}$

MPV also reflects platelet production rate and stimulation through the changes in platelet size since larger platelets are more metabolically and enzymatically active than smaller platelets..$^{20} \mathrm{MPV}$ is a test parameter that may be useful in identifying patients with newly diagnosed invasive ductal breast carcinoma ${ }^{21}$ and elevated MPV value is associated with other markers of platelet activity including: platelet aggregation, increased thromboxane synthesis and $\beta$-thromboglobulin release. ${ }^{22}$

Available evidence have suggested an important role of platelet indices as a marker of disease activity in cancer and several inflammatory diseases ${ }^{17,23,24}$ and increased MPV value has been reported to be associated with disease conditions such as: obesity ${ }^{25}$ hypertension ${ }^{26}$ diabetes mellitus ${ }^{27}$ renal failure ${ }^{28}$ and atrial fibrillation. ${ }^{29}$ P-LCR is inversely related to platelet count and directly related to PDW and MPV..$^{30}$ There is also report on P-LCR suggesting that its prognostic value is similar to that of MPV. ${ }^{30}$

Breast cancer is a common malignancy among women and a serious health problem with 400,000 new cases being diagnosed annually worldwide. ${ }^{31}$ Breast cancer is often divided into stages usually expressed as a number on a scale of 0 through IV with stage 
0 describing non-invasive cancers that remain within their original location and stage IV describing invasive cancers that have spread outside the breast to other parts of the body. Despite multi-approaches in therapeutic management of breast cancer, including surgical, chemotherapy and radiation therapy, breast carcinoma remains a big clinical challenge and platelet indices may be useful in managing patients with breast cancer. ${ }^{21}$ In Yola like most part of Nigeria however, information regarding platelet and platelet indices at various stages of breast cancer is not yet fully studied and documented, this study therefore aims to evaluate platelet count and platelet indices in women at various stages of breast cancer in Yola Nigeria in other highlights the usefulness of platelet count and platelet indices in the clinical management of women with breast cancer in this locality.

\section{Materials and methods}

This study was carried out at medical laboratory department of Federal Medical Center of Yola, in Northeast Nigeria. 143 subjects comprising of 74 women (with mean age of $59.06 \pm 2.14$ years) who were clinically diagnose of breast cancer and 69 clinically healthy women (with a mean age of $53.23 \pm 6.11$ years) participated in this study. All study participants with breast cancer were clinically diagnosed and were referred to the laboratory for evaluation before commencement of therapy. Other informations were retrieved from their medical records. Platelet count and platelet indices were determined using Sysmex XP 300 hematology analyzer. All analyses were performed according to the standard operational procedures.

\section{Sample collection}

Three milliliters of blood were aseptically collected through the antecubital vein of subjects and put in EDTA vacutainer that was further labeled with the patient number, and age. Platelet count and platelet indices for each subject were performed in blood sample put in EDTA vacutainer within one hour of collection.

\section{Sample analyses}

Platelet count and platelet indices estimation: Using the Sysmex XP 300 machine, the procedure for platelet count and platelet indices determination was as follows: EDTA samples were placed in a hematology blood mixer for five minutes and the blood cells were automatically counted through a probe fitted in the Sysmex XP 300 machine. After one minute, the results of platelet count with platelet indices were displayed automatically on color LCD screen on the machine.

\section{Statistical analyses}

Statistical analysis was performed using the SPSS computer software version 20.0 (IBM Chicago, IL, USA). Descriptive values were given as mean and standard error of mean. Categorical variables were expressed as the number of cases and the percentage value. The Student's $t$-test was used to compare the means differences of the estimated parameters and all statistics was carried out at the probability level of 0.05 .

\section{Results}

Table 1 shows the demographic character of the studied population, $17(22.9 \%)$ of the women investigated were married while $09(12.2 \%)$ were divorced and $12(16.2 \%)$ were widows and $07(09.5 \%)$ of the women in this study were primiparous (given birth once) while $02(2.7 \%)$ of the women were Nulliparous (not given birth previously) and $15(20.3 \%)$ of the women were multiparous (has given birth more than once) while $11(14.9 \%)$ of the women were Multigravida (pregnant more than once) and $1.3 \%$ of the women were Nulligravida (not been pregnant previously).

Table I Demography of the studied population

\begin{tabular}{llll}
\hline Parameters & Number observed & $\begin{array}{l}\text { Percentage } \\
\text { prevalence }\end{array}$ & P-value \\
\hline Age & $59.06 \pm 2.14$ years & & 0.05 \\
Married & 17 & $22.90 \%$ & 0.05 \\
Divorce & 9 & $12.20 \%$ & 0.05 \\
Widow & 12 & $16.20 \%$ & 0.05 \\
Primiparous & 7 & $9.50 \%$ & 0.05 \\
Nulliparous & 2 & $2.70 \%$ & 0.05 \\
Multiparous & 15 & $20.30 \%$ & 0.05 \\
Multigravida & 11 & $14.90 \%$ & 0.05 \\
Nulligravida & 1 & $1.30 \%$ & 0.05 \\
\hline
\end{tabular}

Thirty-nine $(52.7 \%)$ of cancer in women observed in this study were at the breast ducts region while $40.5 \%$ of the cancer occurs at the lobules region of the breast and $6.8 \%$ of the cancer occurred at the region between duct and lobules of the breast as shown in Table 2. In addition, $4.1 \%$ and $6.8 \%$ of cancer observed in the women were at stage $o$ and 1 respectively while $36.5 \%$ were at stage 2 and stage 3 of breast cancer was seen in $44.6 \%$ of the studied population (Table 3). Stage 4 of breast cancer occurred in $8.0 \%$ of women. The mean platelet count in women with stage 0 and stage 1 was $207 \pm 23.09 \times 10^{9} / 1$ while the platelet count in women with stage 2 breast cancers was $113 \pm 14.58 \times 10^{9} / 1$ and women with stage 3 and 4 breast cancers had mean platelet counts of $412 \pm 12.50 \times 10^{9} / 1$ (Table 4 ). The mean platelet distribution width (PDW) in women with stage 0 and 1 breast cancer was $11.9 \pm 0.21 \mathrm{fl}$ while the mean PDW of women with stage 2 breast cancer was $13.1 \pm 1.1 \mathrm{fl}$ and PDW of $14.1 \pm 0.30 \mathrm{fl}$ was seen in women with stage 3 and 4 breast cancer. Mean PDW of the control group was $11.5 \pm 1.21 \mathrm{fl}$. In addition, Mean platelet volume (MPV) also varies with stages of breast cancer. The MPV of women with stage 0 and 1 breast cancer was $12.0 \pm 1.20 \mathrm{fl}$ while that of the control group was $09.4 \pm 1.43 \mathrm{fl}$ and MPV of those on stage 2 breast cancer was $13.9 \pm 0.26 \mathrm{fl}$ and women with stage 3 and 4 breast cancer had MPV value of $14.4 \pm 0.08 \mathrm{fl}$. The mean platelet large cell ratio (P-LCR) of women with stage 0 and 1 breast cancer was $32.4 \pm 0.88 \%$ while the P-LCR of those with stage 2 breast cancer was $21.8 \pm 1.64 \%$ and P-LCR of $19.3 \pm 1.13 \%$ was seen in women with stage 3 and 4 breast cancer. However, the mean plaletocrit (PCT) of $0.23 \pm 0.13 \%$ was seen in women with stage 0 and 1 breast cancer while women with stage 2 breast cancer had a mean platetocrit of $0.12 \pm 1.02 \%$ and mean PCT of $0.29 \pm 0.20 \%$ was seen in women with stage 3 and 4 breast cancer while the PCT of the control group was $0.31 \pm 0.11 \%$.

Table 2 Region of cancer in the breast observed

\begin{tabular}{llll}
\hline $\begin{array}{l}\text { Region of cancer } \\
\text { in the breast }\end{array}$ & $\begin{array}{l}\text { Number } \\
\text { observed }\end{array}$ & $\begin{array}{l}\text { Percentage } \\
\text { prevalence }\end{array}$ & p-value \\
\hline Ducts & 39 & $52.70 \%$ & 0.05 \\
Lobules & 30 & $40.50 \%$ & 0.05 \\
$\begin{array}{l}\text { between duct and } \\
\text { lobules }\end{array}$ & 5 & $6.80 \%$ & 0.05 \\
\hline
\end{tabular}


Table 3 Stages of breast cancer observed in the study population

\begin{tabular}{llll}
\hline Stages of breast cancer & Number observed & Percentage prevalence & p-value \\
\hline Stage 0 & 3 & $4.10 \%$ & 0.05 \\
Stage I & 27 & $6.80 \%$ & 0.05 \\
Stage 2 & 33 & $36.50 \%$ & 0.05 \\
Stage 3 & 5 & $44.60 \%$ & 0.05 \\
Stage 4 & 6 & $8.00 \%$ & 0.05 \\
\hline
\end{tabular}

Table 4 Platelet and Platelet indices of women with Stage 0-4 breast cancer (Mean \pm SD)

\begin{tabular}{|c|c|c|c|c|c|}
\hline Parameters & Stage 0, I & Stage II, & Stage III, IV & Control & P-value \\
\hline Age (years) & $59.06 \pm 2.14$ & & & $53.23 \pm 6.11$ & 0.05 \\
\hline Platelet Count (x|09/I) & $207 \pm 23.09$ & $113 \pm 14.58$ & $412 \pm 12.50$ & $317 \pm 19.37$ & 0.05 \\
\hline PDW (fl) & $11.9 \pm 0.21$ & $13.1 \pm 1.1$ & $12.1 \pm 1.30$ & $\mid 1.5 \pm 1.21$ & 0.05 \\
\hline MPV (fl) & $12.0 \pm 1.20$ & $13.9 \pm 0.26$ & $14.4 \pm 0.08$ & $09.4 \pm 1.43$ & 0.05 \\
\hline P-LCR (\%) & $32.4 \pm 0.88$ & $21.8 \pm 1.64$ & $19.3 \pm 1.13$ & $23.4 \pm 2.09$ & 0.05 \\
\hline РCT (\%) & $0.23 \pm 0.13$ & $0.12 \pm 1.02$ & $0.29 \pm 0.20$ & $0.3 I \pm 0.1 I$ & 0.05 \\
\hline Lymphocyte count (\%) & $16.4 \pm 1.33$ & $22.8 \pm 2.17$ & $31.7 \pm 1.90$ & $40.1 \pm 4.29$ & 0.05 \\
\hline Neutrophil count (\%) & $59.6 \pm 2.63$ & $43.7 \pm 2.29$ & $67.3 \pm 0.99$ & $53.3 \pm 3.47$ & 0.05 \\
\hline
\end{tabular}

\section{Discussion}

Platelet and platelet indices at various stages of breast cancer in women was evaluated in this study. The stages of breast cancer when the patients reported to the hospital were $4.1 \%$ and $6.8 \%$ at stage o and stage 1 respectively while $36.5 \%, 44.6 \%$ and $8.0 \%$ were at stage 2,3 and 4 respectively. This indicates that a small portion (4.1 to $6.6 \%$ ) of the studied group reported to the hospital at an early stage of breast cancer while large proportion (36.5 to $44.6 \%)$ reported late to the hospital at stages 3 and 4 . This may be due to lack of knowledge of disease signs, symptoms, progression and high patronage of alternative and folkloric sources of medical treatment in this locality.

Changes in platelet count and platelet indices were observed to vary with different stages of breast cancer. The changes in platelet indices and platelet counts in various stages of breast cancer in this study is due to interaction between platelet and malignant cells. . $^{5,20}$ Higher circulating platelet count was seen in women with stage 3 and 4 breast cancer than in women with stage 0 and 1 breast cancer (Table 4) this is because cancer cells (which increases with stages of cancer) have been known to stimulate platelet proliferation ${ }^{32}$ and this also explains the high platelet count observed in patients with latter (higher) stage of breast cancer compare to that of the control group. High platelet count in cancer was also observed in earlier study by Taucher et al. ${ }^{9}$ and Sierko et al. ${ }^{10}$ In addition, adequate platelet count seen in most stages of cancer is believed to promote the mechanism that facilitates the progression of breast cancer. ${ }^{11} \mathrm{MPV}$ was observed to increases with increase in cancer stage in this present study it is believed that, platelet size as reflected by MPV do increases in direct proportion to breast cancer progression. MPV value can also reflect the level of invasiveness of cancer cell ${ }^{21}$ and high MPV is an indices of inflammation ${ }^{17,23}$ it therefore goes to show that higher MPV value (than that of control observed in this study) may indicates high level of invasiveness and inflammatory processes in women with breast cancer and this inflammatory processes tends to increase as the stages of breast cancer increases. In addition, MPV value is a pointer to level of platelet function and activation ${ }^{16}$ hence, increase in MPV implies increase platelet activation in this group of patients.

The mean P-LCR value was increased in cancer stage 0 and 1 but reduces in breast cancer stage 3 and 4 . An increase P-LCR with increase MPV in stage 0 and 1 indicates that P-LCR may have a similar diagnostic value as $\mathrm{MPV}^{30}$ in early stage of breast cancer. Since PDW is a measure of platelet volume heterogeneity ${ }^{33}$ it goes to show that slightly high PDW value seen in stage 2,3 , and 4 cancer reflects increase heterogeneity in platelet volume and size in these stages of breast cancer in women.

\section{Conclusion}

Platelet count and platelet indices vary at different stages of women breast cancer. The Pattern of variation in values of MPV and P-LCR at stage $0,1,2$ of breast cancer may indicate that these platelet indices may be used as marker of platelet activation, tumor progression and inflammation in women with breast cancer. It is believed that information obtained from this study may help improve clinical management of women with various stages of breast cancer in this locality.

\section{Author's contribution}

Emmanuel Asuquo Etim assisted in research design, article writing, data generation and sample analysis. Abdulakeem Adebayo Yusuf assisted in research design, sample analysis. Mathias Abiodun Emokpae assisted literature review, editing and article writing. Adjekuko Collins Ohwonigho assisted in literature review and Data analysis.

\section{Acknowledgements}

The author wishes to appreciate all the subjects included in this study for their cooperation. We are also grateful to management and 
staffs of Federal Medical center Yola for playing a key role toward the success of this study. The study was sponsored by the authors, the equipment used was provided by the laboratory in which this work was done.

\section{Conflict of interest}

There is no conflict of interest regarding this work among the authors.

\section{References}

1. George JN. Platelets. Lancet. 2000;355(9214):1531-1539.

2. Berger S. Platelet function: A review. I. normal function. Can Med Assoc J. 1970;102(12):1271-1274.

3. Menter DG, Tucker SC, Kopetz S, et al. Platelets and cancer: A casual or causal relationship: revisited. Cancer Metastasis Rev. 2014;33(1):231269.

4. Franco AT, Corken A, Ware J. Platelets at the interface of thrombosis, inflammation, and cancer. Blood. 2015;126(5):582-588.

5. Yan M, Jurasz P. The role of platelets in the tumor microenvironment: From solid tumors to leukemia. Biochim Biophys Acta. 2016;1863(3):392-400.

6. Nash GF, Turner LF, Scully MF, et al. Platelets and cancer. Lancet Oncol. 2002;3(7):425-430.

7. Gay LJ1, Felding-Habermann B. Contribution of platelets to tumour metastasis. Nat Rev Cancer. 2011;11(2):123-134.

8. Stone RL, Nick AM, McNeish IA, et al. Paraneoplastic thrombocytosis in ovarian cancer. $N$ Engl J Med. 2012;366(7):610-618.

9. Taucher S, Salat A, Gnant M, et al. Impact of pretreatment thrombocytosis on survival in primary breast cancer. Thromb Haemost. 2003;89(6):1098-1106.

10. Sierko E, Wojtukiewicz MZ. Platelets and angiogenesis in malignancy. Semin Thromb Hemost. 2004;30(1):95-108.

11. Alonso-Escolano D, Strongin AY, Chung AW, et al. Membrane type-1 matrix metalloproteinase stimulates tumour cell-induced platelet aggregation: role of receptor glycoproteins. Br J Pharmacol. 2004;141(2):241252.

12. Labelle M, Begum S, Hynes RO. Direct signaling between platelets and cancer cells induces an epithelial-mesenchymal-like transition and promotes metastasis. Cancer Cell. 2011;20(5):576-590.

13. Drabsch Y, ten Dijke P. TGF-beta signaling in breast cancer cell invasion and bone metastasis. J Mammary Gland Biol Neoplasia. 2011;16(2):97108.

14. Battinelli EM, Markens BA, Italiano JE. Release of angiogenesis regulatory proteins from platelet alpha granules: modulation of physiologic and pathologic angiogenesis. Blood. 2011;118(5):1359-1369.

15. Buergy D, Wenz F, Groden C, et al. Tumor-platelet interaction in solid tumors. Int J Cancer. 2012;130(12):2747-2760.

16. Nassaji M, Ghahremanfard F, Mirmohammadkhani M, et al. Mean platelet volume and other platelet indices in adults patients with acute pyelonephritis. Asian J Pharm Hea Sci. 2014;4(3):1097-1099.
17. Leader A1, Pereg D, Lishner M. Are platelet volume indices of clinical use? A multidisciplinary review. Ann Med. 2012;44(8):805-816.

18. Babu E, Basu D. Platelet large cell ratio in the differential diagnosis of abnormal platelet counts. See comment in PubMed Commons below Indian J Pathol Microbiol. 2004;47(2):202-205.

19. Buttarello M, Plebani M. Automated blood cell counts: state of the art Am J Clin Pathol. 2008;130(1):104-116.

20. Kannar V, Raja V, Suresh TN. Evaluation of platelet indices in oral squamous cell carcinoma. Clin Cancer Investig J. 2017;6(1):40-43.

21. Mantas D, Kostakis ID, Machairas N, et al. White blood cell and platelet indices as prognostic markers in patients with invasive ductal breast carcinoma. Oncol Lett. 2016;12(2):1610-1614.

22. Bath PM, Butterworth RJ. Platelet size: measurement, physiology and vascular disease. Blood Coagul Fibrinolysis. 1996;7(2):157-161.

23. Gasparyan AY, Ayvazyan L, Mikhailidis DP, et al. Mean platelet volume: a link between thrombosis and inflammation? Curr Pharm Des. 2011;17(1):47-58

24. Griesshammer M, Bangerter M, Sauer T, et al. Aetiology and clinical significance of thrombocytosis: analysis of 732 patients with an elevated platelet count. J Intern Med. 1999;245(3):295-300.

25. Kalay N, Dogdu O, Koc F, et al. Hematologic parameters and angiographic progression of coronary atherosclerosis. Angiology. 2012;63(3):213217.

26. Karabacak M, Dogan A, Turkdogan AK, et al. Mean platelet volume is increased in patients with hypertensive crises. Platelets. 2014;25(6):423426

27. Lippi G, Salvagno GL, Nouvenne A, et al. The mean platelet volume is significantly associated with higher glycated hemoglobin in a large population of unselected outpatients. Prim Care Diabetes. 2015;9(3):226230 .

28. Uçar H, Gür M, Koyunsever NY, et al. Mean platelet volume is independently associated with renal dysfunction in stable coronary artery disease. Platelets. 2014;25(4):274-278.

29. Tekin G, Tekin YK, Sivri N, et al. Mean platelet volume in patients with nonvalvular atrial fibrillation. Blood Coagul Fibrinolysis. 2013;24(5):537-539.

30. Gawlita M, Wasilewski J, Osadnik T, et al. Mean platelet volume and platelet-large cell ratio as prognostic factors for coronary artery disease and myocardial infarction. Folia Cardiologica. 2015;10(6):418-422.

31. Siegel R, Ma J, Zou Z, et al. Cancer statistics. CA Cancer J Clin. 2014;64(1):9-29.

32. Boukerche H, Berthier-Vergnes O, Penin F, et al. Human-melanoma celllines differ in their capacity to release adp and aggregate platelets. $\mathrm{Br} J$ Haematol. 1994;87(4):763-772.

33. Cui MM, Li N, Liu X, et al. Platelet distribution width correlates with prognosis of non-small cell lung cancer. Sci Rep. 2017;7(1):3456. 